\title{
School Connectedness Still Matters: The Association of School Connectedness and Mental Health During Remote Learning Due to COVID-19
}

\author{
Kesha N. Perkins ${ }^{1} \cdot$ Katie Carey ${ }^{1} \cdot$ Emma Lincoln $^{1} \cdot$ Amanda Shih $^{1}$. \\ Rachael Donalds ${ }^{1}$ - Shari Kessel Schneider ${ }^{2}$. Melissa K. Holt ${ }^{1}$. \\ Jennifer Greif Green ${ }^{1}$ (D)
}

Accepted: 21 September 2021 / Published online: 15 October 2021

(c) The Author(s), under exclusive licence to Springer Science+Business Media, LLC, part of Springer Nature 2021

\begin{abstract}
School connectedness is consistently associated with adolescent mental health and well-being. We investigated whether student perceptions of school connectedness were associated with anxiety and depressive symptoms, even during remote learning due to COVID-19. In June of 2020, after 13 weeks of remote learning, 320 middle and high school students in one Massachusetts school district completed an online survey that included questions about their perceptions of school connectedness, social connectedness, and symptoms of anxiety and depression. Students were approximately evenly distributed across grades, with $37 \%$ in middle school (grades 6-8) and 63\% in high school (grades 9-12). School connectedness had a significant negative association with symptoms of anxiety and depression. This association persisted in models controlling for demographic factors and social connectedness. Findings indicate that school connectedness is associated with student mental health, even in the context of remote learning due to COVID-19. Schools engaged in remote learning should consider how to foster school connectedness as a means of supporting youth mental health, particularly given expected increases in the mental health needs of adolescents.
\end{abstract}

Keywords School connectedness $\cdot$ COVID-19 $\cdot$ Mental health $\cdot$ Adolescence

Jennifer Greif Green

jggreen@bu.edu

1 Wheelock College of Education and Human Development, Boston University, 2 Silber Way, Boston, MA 02215, USA

2 Education Development Center, Waltham, MA, USA 


\section{Introduction}

School connectedness refers to "the extent to which students feel personally accepted, respected, included, and supported by others in the school social environment" (Goodenow, 1993; p. 80). Researchers conceptualize school connectedness (and "school belonging," a term with which the phrase is often used interchangeably) as a multifaceted construct that encompasses an individual's feelings of connection with and support from adults and peers, a sense of belonging, and engagement in learning (Page et al., 2021). Studies show that adolescent perceptions of connectedness to school are significantly associated with positive outcomes, including decreased risk of depressive and anxiety symptoms (Shochet et al., 2006). Although positive peer relationships are a component of school connectedness, prior research has distinguished social connectedness from school connectedness, finding evidence that some youth feel connected to peers but not school, and visa-versa, and that school connectedness is more strongly associated with mental health and school outcomes than is social connectedness (Bond et al., 2007).

During spring of 2020, most U.S. students attended schools remotely due to the COVID-19 pandemic, and experts expressed concerns about youth mental health (Golberstein et al., 2020). However, little research exists regarding the association of remote learning with school connectedness and mental health. One study, which interviewed three teachers in New South Wales, Australia, identified challenges to school connectedness during remote learning due to COVID19 , including students struggling with access to technology, shifts in routine, and social isolation (Page et al., 2021). In the current study, we sought to examine school connectedness during a period of remote learning and to assess whether greater school connectedness was associated with fewer anxiety and depressive symptoms. Given the presumed extent of social isolation during school closures (Page et al., 2021), we also sought to understand the association of social connectedness with mental health and the extent to which school connectedness was associated with mental health, once we accounted for social connectedness.

\section{Methods}

We collected data from one Massachusetts school district that provided an online learning module on stress and COVID-19 to students in grades 6-11. We invited all students to complete the module during June 2020, in the final three days of the 2019-2020 school year (at which time Massachusetts schools had been remote for 13 weeks). The module was entirely self-directed and did not involve any interaction with peers, teachers, or other school staff. The module provided students with definitions of stress and anxiety, a series of six tips for reducing stress (e.g., practice relaxation, make time for pleasant activities, be a thoughtful user of technology), four strategies for establishing routine (e.g., create a schedule, establish a sleep routine, create an exercise plan), and information about when and how to ask for help and support. 
Out of 2274 students in the district's middle and high schools, 837 (36.8\%) completed the online learning module and answered a question indicating their grade level. Following module completion, we invited students to participate in a brief research study about their experiences with stress and COVID-19. We provided parents with a description of the research and informed them that their child's participation was optional. In total, 320 students (37.5\% of those completing the module) completed the online survey. Research participants were $59.6 \%$ female, $39.2 \%$ male, and $1.3 \%$ described their gender in another way. In the district as a whole, approximately half of students identified as female (50.9\%), suggesting that females were over-represented among research participants. Students were approximately evenly distributed across grades, with 37.2\% in middle school (grades 6-8) and 62.8\% in high school (grades 9-12). These percentages were similar to the distribution across grades for the larger sample of students who completed the module $(36.6 \%$ middle school, 63.4\% high school). Given that district data indicated students predominantly identified as non-Latino White $(88.1 \%)$, we did not collect individual student data on race/ethnicity to protect participant anonymity.

\section{Measures}

\section{Mental Health}

We assessed anxiety symptoms using the Generalized Anxiety Disorder scale (GAD-2; Kroenke et al., 2007). This brief (2-item) measure has been validated as a screener for generalized anxiety disorder among adolescents (Mossman et al., 2017). We used the Patient Health Questionnaire (PHQ-2; Löwe et al., 2005) to assess depressive symptoms. The PHQ-2 is a 2-item measure that screens for depressed mood and has been validated as a screener for depression among adolescents (Richardson et al., 2010). On both scales, respondents indicated that in the last two weeks they had been bothered by symptoms "not at all" (0), "several days" (1), "more than half the days" (2), or "nearly every day" (3). Sum scores for the GAD-2 and PHQ-2 ranged from 0 to 6 , and a score of 3 or higher indicates elevated risk on each of these scales.

\section{School Connectedness}

We assessed student perceptions of school connectedness using a scale from the National Longitudinal Study of Adolescent to Adult Health (Add Health) and California Healthy Kids Survey. Furlong et al. (2011) found that items demonstrated acceptable reliability and concurrent validity across sociocultural groups. The scale includes five items (e.g., "I feel like I am a part of this school"). Due to remote learning, we excluded one item "I feel safe in my school," given that students were not physically in their schools. We rated items on a scale of "strongly disagree" (1) to "strongly agree" $(5 ; \alpha=0.80)$. 


\section{Social Connectedness}

We assessed social connectedness using the Friendship measure from the Social Relationships battery in the NIH Toolbox (Paolillo et al. 2020). The 5-item scale assesses the perceived availability of friends (e.g., "I feel like I have lots of friends"). We modified two questions to increase relevance to the context of school closures. "I get invited to go out and do things with other people" became "I get invited to do things with other people online (for example, group chats, gaming)." "I have friends to sit with at lunch" became "I have friends to talk with." Items were rated on a scale of "never" (1) to "always" (5). We converted raw sum scores to t-scores $(\alpha=0.87)$.

\section{Analysis}

We first examined mean ratings of each study variable and tested whether there were significant differences by gender and school level. Next, to test associations between social connectedness, school connectedness, and anxiety and depressive symptoms, we entered variables into a series of hierarchical regression models. Model 1 examined the association of anxiety and depressive symptoms with demographic variables (gender, school level, grade level). In Model 2, we added social connectedness. Finally, Model 3 added school connectedness, enabling us to test the association of school connectedness with anxiety and depressive symptoms in a model adjusting for demographic variables and social connectedness.

\section{Results}

Average ratings of anxiety and depressive symptoms were $M=1.59(S D=1.78)$ and $M=1.39(S D=1.45)$, respectively. Roughly one-fifth $(22.8 \%)$ of students had elevated scores (3 or higher) for anxiety and $19.4 \%$ for depressive symptoms. The average rating of school connectedness was $M=3.85(S D=0.76)$. Females reported significantly higher rates of anxiety and depressive symptoms than males, and males reported higher rates of school connectedness than females (Table 1). There were no gender differences in ratings of social connectedness. High school students reported significantly higher rates of anxiety and lower school connectedness than middle school students. There were no school level differences in rates of depressive symptoms or social connectedness.

We entered variables into hierarchical regression models to examine the association of anxiety and depressive symptoms with demographic variables (gender, school level, grade level; Model 1), social connectedness (Model 2), and school connectedness (Model 3). We display results in Table 2. Social connectedness was significantly associated with lower rates of anxiety and depressive symptoms. School connectedness was also significantly associated with lower anxiety and depressive symptoms, even when controlling for demographic variables and social connectedness. 
Table 1 Descriptive statistics by gender and school level

\begin{tabular}{|c|c|c|c|c|c|c|}
\hline & \multicolumn{3}{|l|}{ Gender } & \multicolumn{3}{|l|}{ School Level } \\
\hline & $\begin{array}{l}\text { Female } \\
(n=191) \\
M(S D)\end{array}$ & $\begin{array}{l}\text { Male } \\
(n=125) \\
M(S D)\end{array}$ & $t$ test & $\begin{array}{l}\text { Middle } \\
(n=117) \\
M(S D)\end{array}$ & $\begin{array}{l}\text { High } \\
(n=203) \\
M(S D)\end{array}$ & $t$ test \\
\hline PHQ-2 ${ }^{\mathrm{a}}$ & $1.63(1.53)$ & $0.99(1.22)$ & $4.09 * * *$ & $1.26(1.38)$ & $1.48(1.49)$ & 1.32 \\
\hline GAD- $2^{b}$ & $1.91(1.89)$ & $1.03(1.43)$ & $4.70 * * *$ & $1.16(1.61)$ & $1.83(1.83)$ & $3.40 * * *$ \\
\hline $\begin{array}{l}\text { Social } \\
\text { connectedness }^{\mathrm{c}}\end{array}$ & $47.94(10.91)$ & $48.80(11.58)$ & -0.66 & 48.35 (11.16) & $48.17(11.23)$ & -0.14 \\
\hline $\begin{array}{l}\text { School } \\
\text { connectedness }^{\mathrm{d}}\end{array}$ & $3.79(0.74)$ & $3.98(0.75)$ & $-2.21 *$ & $4.09(0.71)$ & $3.71(0.75)$ & $-4.52 * * *$ \\
\hline
\end{tabular}

${ }^{\mathrm{a}} \mathrm{PHQ}-2=$ Patient Health Questionnaire (range $=0-6$ )

${ }^{\mathrm{b}} \mathrm{GAD}-2=$ Generalized Anxiety Disorder scale (range $=0-6$ )

${ }^{\mathrm{c}}$ Social Connectedness $=$ Friendship measure reported as t-scores $(\mathrm{t}$-score range $=15.7-63.7)$

${ }^{\mathrm{d}}$ School Connectedness $=$ School Connectedness scale average $($ range $=1-5)$

$* p<.05 . * * p<.01 . * * * p<.001$..

\section{Discussion}

Our findings indicate that school connectedness is negatively associated with symptoms of anxiety and depression-even after 13 weeks of remote learning, and during the final three days of the school year. This result underscores the importance of attending to school connectedness in the context of remote learning due to COVID19 or other future epidemics that require school closings. Further, as in other studies (Bond et al., 2007), school connectedness is associated with mental health even when accounting for social connectedness, suggesting that students' sense of connectedness to school contributes to mental health over and above their connection to peers.

Our study has several limitations. Most notably, it is limited by the use of data from a single school district, the brevity of its measures, and its cross-sectional design. In addition, it is possible that students participating in the online module, and thus this study, might be those who were already more connected to school than their nonparticipating peers and perhaps experiencing better mental health and wellbeing. This may have been the case because students were engaged in the module and research study during the final days of the school year. Our results, therefore, may not be representative of all students in the district. Further, participants may have been primed to think about stress before participating in the study because of the title and focus of the module ("Stress and COVID-19"). Students might have also experienced reduced stress from working through the activities in the online module, though it is striking that roughly one-fifth of the sample still reported elevated anxiety symptoms. The fact that our findings are consistent with prior research increases our confidence in the results we present here. In particular, we found higher rates of anxiety and depressive symptoms among females than males and among older than younger adolescents (Kessler et al., 2012). As in previous studies 


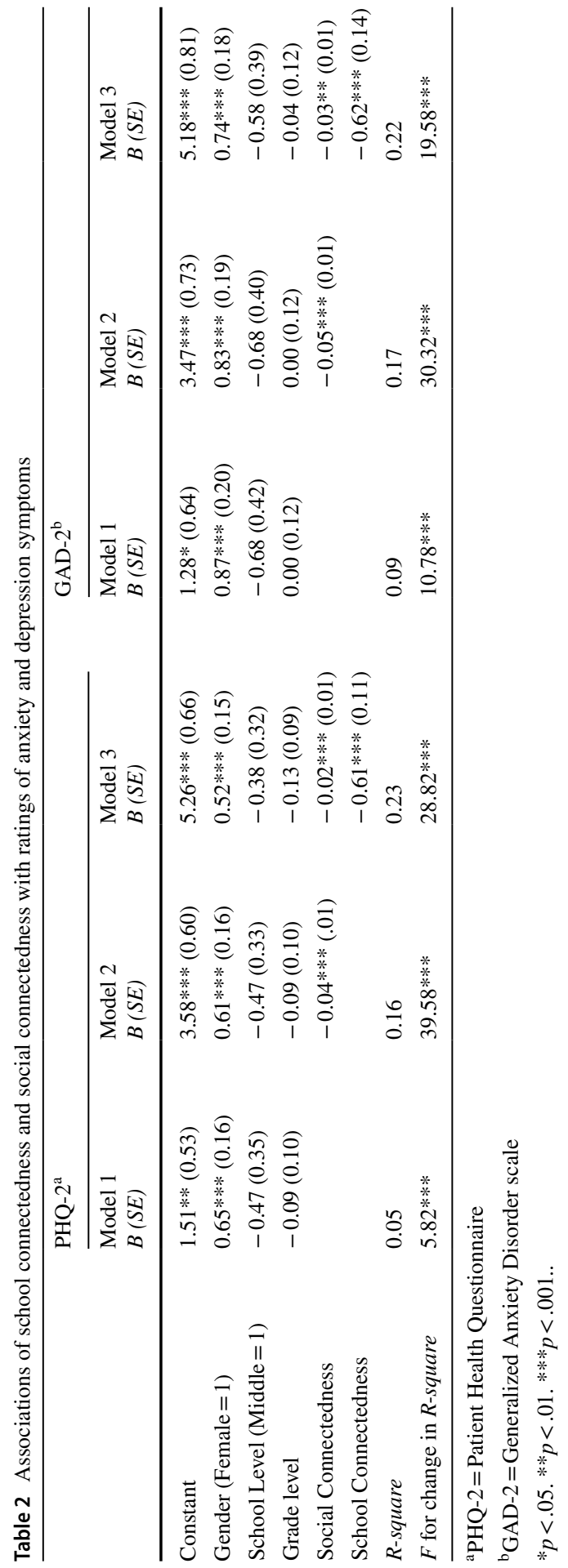


(e.g., Whitlock, 2006), we found that students in high school are less likely to feel connected to school compared to those in middle school.

Of note, rates of elevated anxiety and depressive symptoms were higher in our sample than in some prior community screenings. For example, Richardson et al. (2010), using the PHQ-2 with a sample of adolescents aged 13-17, estimated that $12 \%$ screened positive for depressive symptoms, compared with $19 \%$ in our sample. Higher rates may indicate increased anxiety and depressive symptoms during the COVID-19 pandemic, as has been found in other research with adolescents (Magson et al., 2021). In contrast, the average rating of school connectedness in our sample (3.85) was slightly higher than the average rating from the National Longitudinal Study of Adolescent Health (3.64; McNeely et al., 2002). That said, our study did not include the item on school safety.

Overall, our findings suggest that schools should prioritize maintaining and improving school connectedness in remote learning contexts. Page and colleagues (2021) suggest strategies to improve school connectedness during remote instruction due to COVID-19, which include prioritizing opportunities for students to connect with classmates and building communication systems between school staff and adults at home. As educators and researchers reflect on this period of remote learning, it will be important to systematically document the creative strategies used to increase student connectedness to school, and to engage in intervention research to identify which strategies are both most effective and most feasible to sustainably enhance school connectedness.

Acknowledgements We are grateful for support from the Undergraduate Research Opportunities Program at Boston University.

\section{Declarations}

Conflict of Interest The authors declare they have no conflict of interest.

\section{References}

Bond, L., Butler, H., Thomas, L., Carlin, J., Glover, S., Bowes, G., et al. (2007). Social and school connectedness in early secondary school as predictors of late teenage substance use, mental health, and academic outcomes. Journal of Adolescent Health, 40(4), 357.e9-357.e18. https://doi.org/10.1016/j. jadohealth.2006.10.013

Furlong, M. J., O’Brennan, L. M., \& You, S. (2011). Psychometric properties of the add health school connectedness scale for 18 sociocultural groups. Psychology in the Schools, 48(10), 986-997. https://doi.org/10.1002/pits.20609

Golberstein, E., Wen, H., \& Miller, B. F. (2020). Coronavirus disease 2019 (COVID-19) and mental health for children and adolescents. JAMA Pediatrics. https://doi.org/10.1001/jamapediatrics.2020. 1456

Goodenow, C. (1993). The psychological sense of school membership among adolescents: Scale development and educational correlates. Psychology in the Schools, 30(1), 79-90. https://doi.org/10.1002/ 1520-6807(199301)30:1

Kessler, R. C., Avenevoli, S., Costello, E. J., Georgiades, K., Green, J. G., Gruber, M. J., et al. (2012). Prevalence, persistence, and sociodemographic correlates of DSM-IV disorders in the national comorbidity survey replication adolescent supplement. Archives of General Psychiatry, 69(4), 372380. https://doi.org/10.1001/archgenpsychiatry.2011.160 
Kroenke, K., Spitzer, R. L., Williams, J. B. W., Monahan, P. O., \& Löwe, B. (2007). Anxiety disorders in primary care: Prevalence, impairment, comorbidity, and detection. Annals of Internal Medicine, 146(5), 317. https://doi.org/10.7326/0003-4819-146-5-200703060-00004

Löwe, B., Kroenke, K., \& Gräfe, K. (2005). Detecting and monitoring depression with a two-item questionnaire (PHQ-2). Journal of Psychosomatic Research, 58(2), 163-171. https://doi.org/10.1016/j. jpsychores.2004.09.006

Magson, N. R., Freeman, J. Y., Rapee, R. M., Richardson, C. E., Oar, E. L., \& Fardouly, J. (2021). Risk and protective factors for prospective changes in adolescent mental health during the COVID-19 pandemic. Journal of Youth and Adolescence, 50(1), 44-57.

McNeely, C. A., Nonnemaker, J. M., \& Blum, R. W. (2002). Promoting school connectedness: Evidence from the national longitudinal study of adolescent health. Journal of School Health, 72(4), 138-146.

Mossman, S. A., Luft, M. J., Schroeder, H. K., Varney, S. T., Fleck, D. E., Barzman, D. H., Gilman, R., DelBello, M. P., \& Strawn, J. R. (2017). The Generalized Anxiety Disorder 7-item scale in adolescents with generalized anxiety disorder: Signal detection and validation. Annals of Clinical Psychiatry: Official Journal of the American Academy of Clinical Psychiatrists, 29(4), 227-234A.

Page, A., Charteris, J., Anderson, J., \& Boyle, C. (2021). Fostering school connectedness online for students with diverse learning needs: Inclusive education in Australia during the COVID-19 pandemic. European Journal of Special Needs Education, 1-15.

Paolillo, E. W., McKenna, B. S., Nowinski, C. J., Thomas, M. L., Malcarne, V. L., \& Heaton, R. K. (2020). NIH toolbox ${ }^{\circledR}$ emotion batteries for children: Factor-based composites and norms. Assessment 27(3), 607-620.

Richardson, L. P., Rockhill, C., Russo, J. E., Grossman, D. C., Richards, J., McCarty, C., et al. (2010). Evaluation of the PHQ-2 as a brief screen for detecting major depression among adolescents. Pediatrics, 125(5), e1097-e1103. https://doi.org/10.1542/peds.2009-2712

Shochet, I. M., Dadds, M. R., Ham, D., \& Montague, R. (2006). School connectedness is an underemphasized parameter in adolescent mental health: Results of a community prediction study. Journal of Clinical Child and Adolescent Psychology, 35(2), 170-179. https://doi.org/10.1207/s15374424j ccp3502_1

Whitlock, J. L. (2006). Youth perceptions of life at school: Contextual correlates of school connectedness in adolescence. Applied Developmental Science, 10(1), 13-29. https://doi.org/10.1207/s1532480xa ds1001_2

Publisher's Note Springer Nature remains neutral with regard to jurisdictional claims in published maps and institutional affiliations. 